\title{
Neuropathic Pain Registries Improve Pain Management and Provide More Efficacious Planning of Healthcare Services
}

\author{
Athina Vadalouca · Martina Rekatsina
}

Received: March 6, 2020 / Published online: April 17, 2020

(C) The Author(s) 2020

\section{ABSTRACT}

The first official health registry dates back to the 19 th century and was proven to be very useful for gathering important information regarding a specific disease. Since then, data collection through registries is gaining more popularity, as it can offer useful information not only to health providers but also to healthcare planning services. Health registries could come along with randomized controlled trials and support or reject their findings in the "real world". Pain registries and neuropathic pain registries have proven to be very potent weapons in the armory of the pain specialist and are growing rapidly, offering substantial information for this challenging pain entity.

Keywords: Healthcare services design; Neuropathic pain registries; Pain management improvement

Enhanced Digital Features To view enhanced digital features for this article go to https://doi.org/10.6084/ m9.figshare.12063687.

A. Vadalouca

Head of Pain and Palliative Care Center, Athens

Medical Center Hospital, Athens, Greece

M. Rekatsina ( $\square)$

Moorfields Eye Hospital, NHS Trust, London, UK

e-mail: mrekatsina@gmail.com

\section{Key Summary Points}

In the last few years, the use of registries and the recognition of their importance is witnessing an increase.

The roots of register-based medicine can be identified to Norway in 1856 .

Registries could be an advantageous alternative to randomized controlled trials as they gather information from the real world, with greater sample size and no time limitations.

Pain registries lead to a better understanding of treatment benefits in certain populations or different pain entities and identify the effectiveness of specific treatment procedures or polypharmacy remedies as well.

The high prevalence of neuropathic pain in surviving cancer patients as well as the continuously rising numbers of patients with chronic pain with a neuropathic component highlights the importance of neuropathic pain registries. 


\section{COMMENTARY}

Regardless of the disease, health registries are valuable tools for ameliorating clinical conditions and supporting clinical and epidemiological research [1]. Recently, the lack of resources for development of new treatments has led to the development of big data analysis, where registries could prove very useful [2]. Apart from supporting the latter, health registries can be vital for the planning of healthcare services [1].

Over the last few years, the use of registries and the recognition of their importance are increasing. Notably, the United States Food and Drug Administration risk minimization action plan has identified health registries as important tools to significantly reduce identified product risk [3, 4]. Moreover, in a survey conducted by the International Society for Pharmacoeconomics and Outcomes Research, a high percentage of interviewees responded that institutional agencies (academia, a contract research organization, the pharmaceutical industry, medical device industry, etc.) are presently associated with the establishment and management of at least one patient registry [5].

When it comes to establishing a register, it is worth looking into the origin of register-based medicine. Historically, a collection of individual patient data may have served as a wellestablished tool in medicine [6] and in order to create a register, a permanent record should be established, according to the World Health Organization nomenclature [7]. This requires longitudinal follow-up of patients and basic statistical analyses for epidemiological data and information on clinical history [7]. Hence, improving vigilance, health care, and research should be the primary aims of a health-register.

The roots of register-based medicine can be identified to Norway, namely the National Leprosy Registry, which was created in 1856, and represents the first national patient register in the world $[8,9]$. As in the 19th century leprosy was a severe health problem in the rural western regions of Norway, an important decision was made that all the patients examined and found to be infected with leprosy would be systematically registered, resulting in the establishment of a National Leprosy Register, a complete medical innovation, not only in Norway but also in an international perspective. It is worth mentioning that some patients were apprehensive of social exposure because of the register and tended to avoid registration [10]. The main aim of that register was to understand better the spread of the disease and influence disease control programs [8].

Moreover, another important use of registries is to enhance the medical information that we get from randomized controlled trials (RCTs). In medical research, it is well recognized that RCTs are the gold-standard procedure to prove the efficacy of interventions. However, it might be difficult to generalize the results obtained from these trials in routine clinical practice. Particularly, RCTs impose strict criteria for the inclusion and exclusion of patients during the selection process. Furthermore, the assessment of interventions is performed under highly controlled settings [11] and in some occasions RCTs do not detect all the possible adverse events due to limited sample size or time limitations [12]. Therefore, patient registries are worthy alternatives to effectively resolve the above-mentioned difficulties and to initiate best practices in pain medicine. Moreover, it is a fact that the "real-world" data incorporated in patient registries, during the course of patient care, could provide considerable advantages that complement the findings of RCTs. Thus, significant information can be obtained to ascertain the safety and efficacy of interventions, especially with diversified patient populations (different ages, multiple comorbidities, etc.) and clinical situations [13]. According to the above, registries can provide invaluable information about the utility of a treatment and its efficacy, but the data must be examined with caution. As a result, it is suggested that a registry could not provide the same level of control and interpretation as RCTs, since a registry's data might be undermined by missing data or a host of confounding factors that could interact with the recorded adverse events.

Patient registries represent interesting and alternative research avenues and are becoming increasingly popular in many areas of medicine, 
including pain medicine, as well as in the management of acute postoperative pain [14] and postsurgical neuropathic pain [15]. Taking all the above into consideration, in our opinion, pain registries would lead to better understanding of treatment benefits in certain populations and different pain entities and also the effectiveness of specific treatment procedures or polypharmacy remedies. There are quite a few examples of patient registries in pain medicine, of which the PAIN OUT is the first international acute pain registry [14]. Other examples include the "Oslo University Hospital Pain Registry" [16], a valuable existing digital chronic pain registry that provides data of thousands of patients, and the Quebec Pain Registry (QPR), a large research database of patients suffering from various chronic pain (CP) syndromes in the province of Quebec (Canada). The above registry constitutes a comprehensive tool for conducting research in a "real-world" context. It contains data on the clinical evolution of thousands of patients and provides the opportunity of answering important research questions on various aspects of CP (or specific pain syndromes) and its management [17]. Another pain registry that was established in 2015 in Denmark, the PainData, aims to assist clinical decision-making, and facilitate quality assurance and research projects to improve understanding and optimize treatment of patients with chronic pain [18]. Finally, the "Special Registry for Patients with Chronic Neuropathic Pain" was also established by the Hellenic Society of Pain Management and Palliative Care (PARH.SY.A) with the data of thousands of patients with chronic neuropathic pain in Greece $[19,20]$. For example, the Greek Pain Neuropathic Registry includes patient information such as baseline patient data (demographics and social-financial data), medical history, relevant family history, type of chronic pain, type of neuropathic pain, history of neuropathic pain, pain medication, interventional techniques, and other treatments [19].

Besides the obvious clinical benefits, these registries might be used for conducting pharmaco-economic studies. Cost-effectiveness of interventions is important in the planning and use of health care services and available resources [21].

To further support the aforementioned and to highlight the importance of neuropathic pain registries specifically, we provide one example from a Spanish neuropathic pain registry. Data from this registry were analyzed in order to assess the etiology and the cost of management of patients with neuropathic pain. The results showed that neuropathic pain results in substantial utilization of health resources, particularly by those who were referred by primary care specialists to pain clinics for pain management [22]. However, the writers compared these results with patients whose pain is primarily managed in pain clinics and it seems that the extra health care cost for medication for the referred patients is being offset by the lower costs of other components of pain management, eventually generating similar mean monthly total costs [22]. Moreover, a recent big cohort study that was conducted in Norway and included data from two nationwide registers, the Cancer Registry of Norway and the Norwegian Prescription Database, revealed that in cancer survivors there is a high prevalence of gabapentinoids. The latter, according to the writers, is indicative of increased prevalence of neuropathic pain and further supports the importance of the existence of neuropathic pain registries [23].

Taking all the above into consideration, the existence and usage of neuropathic pain registries to their full extent could not only lead to better patient management but also serve as a useful tool for the development and planning of pain management services. Useful information, apart from the prevalence and the treatment costs, than could be gathered from neuropathic pain registries could be medication usage for specific types of neuropathic pain, medication tolerance or failure, medication side effects, coping strategies of patients (like distraction strategies or trigger point massaging for myofascial pain), usage of health care and pain services, success or failure of pain procedures, and many other important information [24-26].

Of utmost importance is that along with the many benefits of health registries in research 
and health planning, we should also acknowledge the sensitive nature of information stored in such registries and the potential risk of information leak [27]. The valid recent concerns about privacy and data protection could limit a registry's use and affect the willingness of patients to share their information [28]. For instance, many patients have concerns regarding the potential economic harm resulting from discrimination in health insurance and employment or that they would have to pay out of pocket for care that is covered by insurance [29]. Therefore, as clinicians and researchers, we should be extremely grateful to our patients for sharing their information and treat these sensitive data with due respect. Clinicians and researchers should always look for ways to improve data sharing that would minimize the risk of information leak. Establishment and maintenance of pain registries are crucial for clinical and research applications. Epidemiological, clinical, and economical studies will be feasible with the data obtained by them; however, more importantly, patients will receive better and personalized care for pain management.

\section{ACKNOWLEDGEMENTS}

We thank the Croatian Chamber of Pharmacists for their support.

Funding. No funding or sponsorship was received for this study or publication of this article.

Authorship. All named authors meet the International Committee of Medical Journal Editors (ICMJE) criteria for authorship for this article, take responsibility for the integrity of the work as a whole, and have given their approval for this version to be published.

Disclosures. Athina Vadalouca and Martina Rekatsina have nothing to disclose.

Compliance with Ethics Guidelines. This article is based on previously conducted studies and does not contain any studies with human participants or animals performed by any of the authors.

Data Availability. Data sharing is not applicable to this article, as no datasets were generated or analyzed during the current study.

Open Access. This article is licensed under a Creative Commons Attribution-NonCommercial 4.0 International License, which permits any non-commercial use, sharing, adaptation, distribution and reproduction in any medium or format, as long as you give appropriate credit to the original author(s) and the source, provide a link to the Creative Commons licence, and indicate if changes were made. The images or other third party material in this article are included in the article's Creative Commons licence, unless indicated otherwise in a credit line to the material. If material is not included in the article's Creative Commons licence and your intended use is not permitted by statutory regulation or exceeds the permitted use, you will need to obtain permission directly from the copyright holder. To view a copy of this licence, visit http://creativecommons.org/licenses/by$\mathrm{nc} / 4.0 /$.

\section{REFERENCES}

1. Hoque D, Kumari V, Hoque M, Ruseckaite R, Romero L, Evans SM. Impact of clinical registries on quality of patient care and clinical outcomes: a systematic review. PLoS ONE. 2017;12(9):e0183667. https://doi.org/10.1371/journal.pone.0183667.

2. Dewdney SB, Lachance J. Electronic records, registries, and the development of "Big Data": crowdsourcing quality toward knowledge. Front Oncol. 2017;6:268. https://doi.org/10.3389/fonc.2016. 00268 .

3. Regulatory Information of Food and Drug Administration Center. 2005. https://www.fda.gov/ regulatory-information/search-fda-guidancedocuments/development-and-use-riskminimization-action-plans. Accessed 3 Mar 2020

4. Guidance for Industry Development and Use of Risk Minimization Action Plans US Department of Health and Human Services Food and Drug 
Administration Center for Drug Evaluation and Research (CDER) Center for Biologics Evaluation and Research (CBER) March. Clinical Medical. 2005. https://www.fda.gov/media/71268/ download. Accessed 3 Mar 2020

5. McGhan WF, Al M, Doshi JA, Kamae I, Marx SE, Rindress D. The ISPOR good practices for quality improvement of cost-effectiveness research task force report. Value Health. 2009;12(8):1086-99.

6. Sandvik H. Leprosy and heredity. Reflections of a district physician in 1884. Tidsskr Nor Laegeforen. 1992;112(30):3799-801.

7. WHO Expert Committee on Health Statistics and World Health Organization. Epidemiological methods in the study of chronic diseases : eleventh report of the WHO Expert Committee on Health Statistics [meeting held in Geneva from 15 to 21 November 1966]. World Health Organization. 1967. https://apps.who.int/iris/handle/10665/ 40658. Accessed 20 Feb 2020.

8. Irgens LM, Bjerkedal T. Epidemiology of leprosy in Norway: the history of The National Leprosy Registry of Norway from 1856 until today. Int J Epidemiol. 1973;2(1):81-9.

9. Irgens LM. Leprosy in Norway: an interplay of research and public health work. Int J Lepr Other Mycobact Dis. 1973;41(2):189-98.

10. Irgens LM. The origin of registry-based medical research and care. Acta Neurol Scand Suppl. 2012;195:4-6.

11. Mulder R, Singh AB, Hamilton A, Das P, Outhred T, Morris G, Lyndon B. The limitations of using randomised controlled trials as a basis for developing treatment guidelines. Evid Based Ment Health. 2018;21(1):4-6.

12. Craig $\mathrm{R}$, Rees J. Providing better evidence in orthopaedic surgery: RCTs, registries, or both. The BMJ opinion, web article. 2019. https://blogs.bmj. com/bmj/2019/02/20/providing-better-evidenceorthopaedic-surgery-rcts-registries-both/. Accessed 03 Mar 2020

13. Hoque DME, Kumari V, Hoque M, Ruseckaite R, Romero L, Evans SM. Impact of clinical registries on quality of patient care and clinical outcomes: a systematic review. PLoS ONE. 2017;12(9):0183667.

14. Zaslansky R, Rothaug J, Chapman CR, Bäckström R, Brill S, Fletcher D, Fodor L, Gordon DB, Komann M, Konrad C, Leykin Y, Pogatski-Zahn E, Puig MM, Rawal N, Ullrich K, Volk T, Meissner W. PAIN OUT: the making of an international acute pain registry. Eur J Pain. 2015;19(4):490-502.
15. Stamer UM, Ehrler M, Lehmann T, Meissner W, Fletcher D. Pain-related functional interference in patients with chronic neuropathic postsurgical pain: an analysis of registry data. Pain. 2019;160(8): 1856-65.

16. Granan LP, Reme SE, Jacobsen HB, Stubhaug A, Ljoså TM. The Oslo University Hospital Pain Registry: development of a digital chronic pain registry and baseline data from 1712 patients. Scand J Pain. 2019;19(2):365-73.

17. Choinière $M$, Ware $M A$, Pagé $M G$, Lacasse $A$, Lanctôt $\mathrm{H}$, Beaudet N, Boulanger A, Bourgault P, Cloutier C, Coupal L, De Koninck Y, Dion D, Dolbec P, Germain L, Martin V, Sarret P, Shir Y, Taillefer MC, Tousignant B, Trépanier A, Truchon R. Development and Implementation of a Registry of Patients attending multidisciplinary pain treatment clinics: The Quebec Pain Registry. Pain Res Manag. 2017. https://doi.org/10.1155/2017/8123812.

18. Vægter HB, Høybye MT, Larsen SK, Hansen OB, Pedersen CB, Jensen PBF, Handberg G. PainData: a clinical pain registry in Denmark. Scand J Pain. 2017;16(1):185-185.

19. Vadalouca A, Rekatsina M, Siafaka I. Neuropathic pain registries: lessons learned from international, European or national initiatives. Reg Anesth Pain Med. 2019;44:A56-A5757.

20. Greek registry for neuropathic pain website (Greek only). https://grpalliative.gr/mnp/. Accessed $03 \mathrm{Mar}$ 2020

21. Nelson EC, Dixon-Woods M, Batalden PB, Homa K, Van Citters AD, Morgan TS, Eftimovska E, Fisher ES, Ovretveit J, Harrison W, Lind C, Lindblad S. Patient focused registries can improve health, care, and science. BMJ (Clin Res ed). 2016;354:i3319. https:// doi.org/10.1136/bmj.i3319.

22. Rodriguez MJ, Garcia AJ. A registry of the aetiology and costs of neuropathic pain in pain clinics: results of the Registry of Etiologies and Costs (REC) in Neuropathic Pain Disorders study. Clin Drug Investig. 2007;27(11):771-82.

23. Fredheim OM, Skurtveit S, Loge JH, Sjøgren $P$, Handal M, Hjellvik V. Prescription of analgesics to long-term survivors of cancer in early adulthood, adolescence and childhood in Norway: a national cohort study. Pain. 2020. https://doi.org/10.1097/j. pain.0000000000001800.

24. Henwood P, Ellis JA. Chronic neuropathic pain in spinal cord injury: the patient's perspective. Pain Res Manag. 2004;9(1):39-45.

25. Pérez C, Navarro A, Saldaña MT, Wilson K, Rejas J. Modeling the predictive value of pain intensity on 
costs and resources utilization in patients with peripheral neuropathic pain. Clin J Pain. 2015;31(3):273-9.

26. Malhotra V, Glare P, Tan KS, Wills J, Gulati A, Puttanniah V, Inturrisi C. The Tri-Institutional Pain Registry-analysis of outpatient pain management at a specialized cancer center. Pain Med. 2017;18(12):2474-84.

27. Channel news Asia website: the leaking of Singapore's HIV registry records and the hunt for Mikhy Farrera Brochez: a timeline. 2019. https://www. channelnewsasia.com/news/singapore/mikhyfarrera-brochez-hiv-registry-leak-timeline-ler-tecksiang-11180290. Accessed 03 Mar 2020
28. Gliklich RE, Dreyer NA, Leavy MB, editors. Registries for evaluating patient outcomes: a user's guide. 3rd ed. Rockville: Agency for Healthcare Research and Quality (US); 2014.

29. Institute of Medicine (US). Committee on Health Research and the Privacy of Health Information: The HIPAA Privacy Rule. In: Nass SJ, Levit LA, Gostin LO, editors. Beyond the HIPAA privacy rule: enhancing privacy, improving health through research: the value and importance of health information privacy. 2nd ed. Washington: National Academies Press; 2009. 